\title{
Low-Cost Radiator for Fission Power Thermal Control
}

\author{
Taylor Maxwell, ${ }^{1}$ Calin Tarau ${ }^{2}$, William Anderson ${ }^{3}$, and John Hartenstine ${ }^{4}$ \\ Advanced Cooling Technologies, Inc., Lancaster, PA, 17601 \\ Theodore Stern $^{5}$ and Nicholas Walmsley ${ }^{6}$ \\ Vanguard Space Technologies, Inc., San Diego, CA, 92126 \\ Maxwell Briggs ${ }^{7}$ \\ NASA Glenn Research Center, Cleveland, $\mathrm{OH}, 44135$
}

\begin{abstract}
NASA Glenn Research Center (GRC) is developing fission power system technology for future Lunar surface power applications. The systems are envisioned in the 10 to $100 \mathrm{~kW}_{\mathrm{e}}$ range and have an anticipated design life of 8 to 15 years with no maintenance. NASA GRC is currently setting up a $55 \mathrm{~kW}_{\mathrm{e}}$ non-nuclear system ground test in thermal-vacuum to validate technologies required to transfer reactor heat, convert the heat into electricity, reject waste heat, process the electrical output, and demonstrate overall system performance. Reducing the radiator mass, size, and cost is essential to the success of the program. To meet these goals, Advanced Cooling Technologies, Inc. (ACT) and Vanguard Space Technologies, Inc. (VST) are developing a single facesheet radiator with heat pipes directly bonded to the facesheet. The facesheet material is a graphite fiber reinforced composite (GFRC) and the heat pipes are titanium/water. By directly bonding a single facesheet to the heat pipes, several heavy and expensive components can be eliminated from the traditional radiator design such as, POCO ${ }^{\mathrm{TM}}$ foam saddles, aluminum honeycomb, and a second facesheet. A two-heat pipe radiator prototype, based on the single facesheet direct-bond concept, was fabricated and tested to verify the ability of the direct-bond joint to withstand coefficient of thermal expansion (CTE) induced stresses during thermal cycling. The thermal gradients along the bonds were measured before and after thermal cycle tests to determine if the performance degraded. Overall, the results indicated that the initial uniformity of the adhesive was poor along one of the heat pipes. However, both direct bond joints showed no measureable amount of degradation after being thermally cycled at both moderate and aggressive conditions.
\end{abstract}

\section{Introduction}

$\mathrm{N}$ ASA Glenn Research Center (GRC) is developing fission power system technology for future Lunar surface power applications. The systems are envisioned in the 10 to $100 \mathrm{~kW}_{\mathrm{e}}$ range and have an anticipated design life of 8 to 15 years with no maintenance. A nominal lunar fission surface power design has been developed and is shown in Figure 1 (Mason, Poston, and Qualls, 2008). The nuclear reactor supplies thermal energy to Brayton (or Stirling) convertors to produce electricity, and uses a heat pipe radiator to reject the waste heat generated by the convertors. The radiator panels must reject heat from both sides to achieve the highest efficiency; therefore, the optimum mounting position is vertical. The radiator panels contain embedded heat pipes to improve thermal transfer efficiency. Since the heat pipe evaporator is on the bottom, the heat pipes are gravity aided and can work as a thermosyphon. This is advantageous because the heat pipe is not required to pump the working fluid back to the evaporator against gravity. Heat is supplied to the heat pipes through a titanium/water heat exchanger that is coupled with the coolant loop in the radiator.

\footnotetext{
${ }^{1}$ R\&D Engineer, Aerospace Products, 1046 New Holland Ave.

${ }^{2}$ Lead Engineer, Aerospace Products, 1046 New Holland Ave., AIAA Member

${ }^{3}$ Chief Engineer, Aerospace Products, 1046 New Holland Ave, AIAA Member.

${ }^{4}$ Manager of Aerospace Products, 1046 New Holland Ave, AIAA Member.

${ }^{5}$ Lead Engineer, 9431 Dowdy Drive

${ }^{6}$ Principle Investigator, 9431 Dowdy Drive

${ }^{7}$ Program Manager, 21000 Brookpark Road
} 


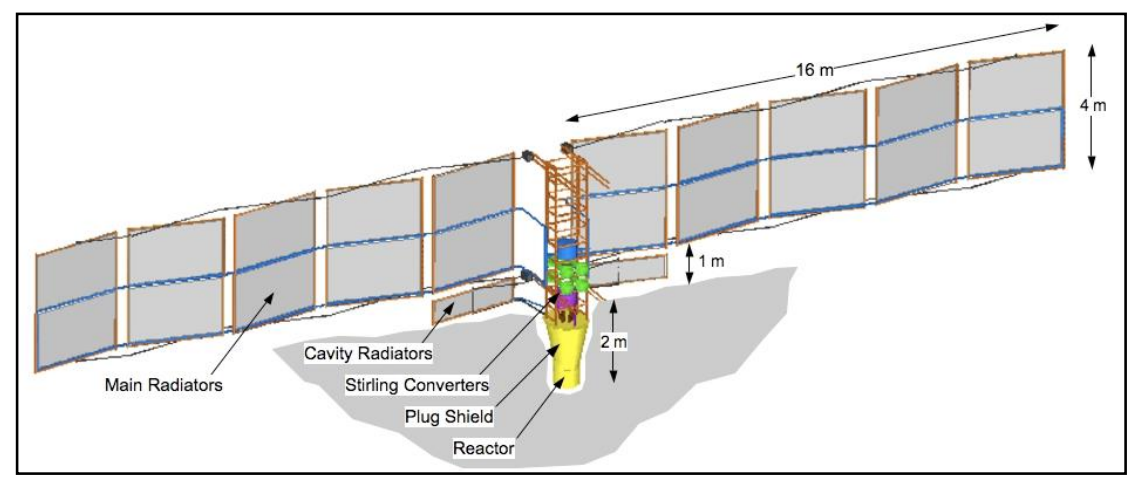

Figure 1. Fission surface power system concept (Mason, Poston, and Qualls, 2008).

Currently, NASA GRC is putting together a Fission Power System Technology Demonstration Unit (Mason et al., 2012). The TDU is a non-nuclear demonstration unit that will be tested in thermal-vacuum to demonstrate integrated system performance. The primary goals for the early systems are low cost, high reliability and long life. To help achieve these goals, ACT, NASA GRC and VST are developing a single facesheet direct-bond radiator (see Figure 2). The radiator will have Variable Conductance Heat Pipes (VCHPs) made from titanium and will use water as the working fluid.

There are several aspects of the single facesheet radiator that need to be studied to verify the feasibility. For example, in lunar applications, the sink temperature is known to vary over a wide range $(114-212 \mathrm{~K}$ at Shackleton Crater). As a result, the bond must be able to withstand stresses induced by the CTE mismatch between the GFRC and the titanium heat pipes. The main purpose of this study was to demonstrate that a GFRC facesheet could be directly bonded to the titanium heat pipes with reasonable conformity, and to determine if the direct bond joint would experience degradation after thermal cycling.

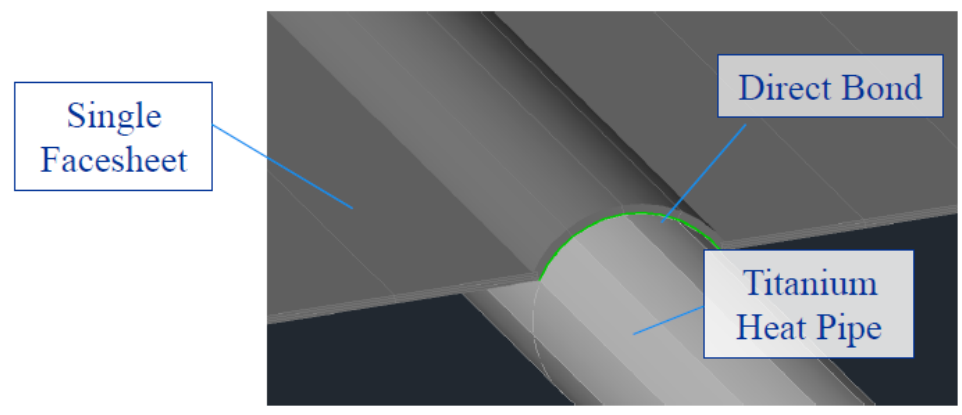

Figure 2. Single-facesheet radiator design with direct bonding of the facesheet to the heat pipes. The stiffeners are not shown (Briggs, 2012).

\section{Background on Variable Conductance Heat Pipe Radiators}

As mentioned before the radiator presented in this paper uses VCHPs to passively limit the evaporator temperature range during varying heat load or changing sink temperature conditions. A simple VCHP is shown below in Figure 3. It is similar to a conventional heat pipe but has a reservoir and controlled amount of non-condensable gas (NCG) inside the reservoir. When the heat pipe is operating, the NCG is swept toward the condenser end of the heat pipe by the flow of the working fluid vapor. The NCG then blocks the working fluid from reaching a portion of the condenser. The VCHP works by varying the amount of condenser available to the working fluid. As the evaporator temperature increases, the vapor temperature (and pressure) rises, which compresses the NCG (Figure 3 top) and thus more condenser is exposed to the working fluid. This increases the effective conductivity of the heat pipe and drives the temperature of the evaporator down. Conversely, if the evaporator cools, the vapor pressure drops and the NCG expands (Figure 3 bottom). This reduces the amount of available condenser, decreases the effective heat pipe conductivity, and increases the evaporator temperature. 


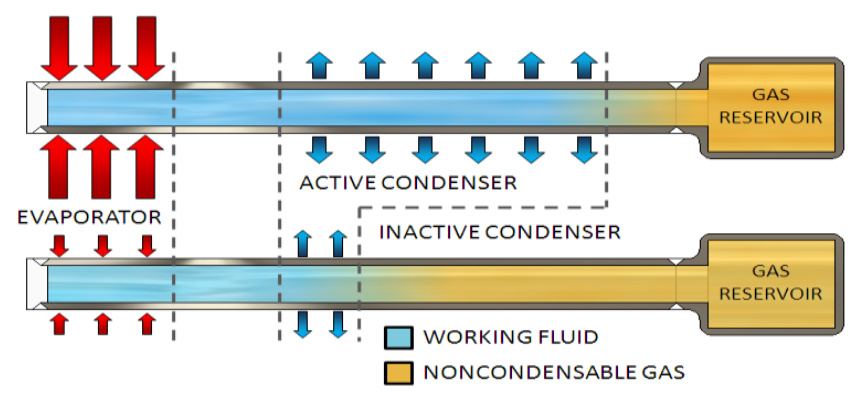

Figure 3. The working of a VCHP is illustrated. At high heat load, the temperature dependent saturation pressure of the working fluid is high and compresses the NCG into the reservoir. At lower heat input the working fluid temperature and pressure is lower, and the non-condensable gas expands into the condenser.

ACT developed a traditional VCHP radiator for fission surface power applications under a previous NASA SBIR Phase II program (Contract No. NNX09CA43C) (see Figure 4a). A full-scale radiator panel was designed, fabricated and tested during the Phase II program. This included thermal performance testing in a vacuum at NASA GRC. The full-scale panel utilized five VCHPs embedded in POCO ${ }^{\mathrm{TM}}$ foam saddles and two Graphite Fiber Reinforced Composite (GFRC) facesheets epoxied to either side of the saddle. Aluminum honeycomb was then used as a stiffener to fill the void space between VCHP/foam saddle assemblies. A top down view of the VCHP radiator can be seen in Figure 4b.

The radiator panel was designed to operate in the 370 to $400 \mathrm{~K}$ temperature range and uses a novel evaporator design to integrate with the fission reactor coolant manifold. The use of embedded VCHPs instead of Constant Conductance Heat Pipes (CCHPs) allowed the radiator to operate over a wide range of sink conditions and also enabled the radiator panel to start up from a frozen state. The temperature on the lunar surface can vary from 50K during lunar night to $330 \mathrm{~K}$ during lunar day. The variable conductance nature of the VCHP radiator allows the system to reject heat during the lunar day, and adjust the heat rejection during the lunar night with the colder heat sink. This is achieved through the use of a non-condensable gas (NCG) located in a reservoir at the end of the VCHP condenser. As ambient temperatures begin to decrease, so does the operating temperature of the working fluid contained within the VCHP. This decrease in temperature causes the vapor pressure of the working fluid to also decrease and allows the NCG contained in the reservoir to expand, reducing the effective length of the condenser. Conversely, as the ambient temperature begins to increase, the operating temperature and vapor pressure of the working fluid increases. This results in compression of the NCG into the reservoir and increases the effective length of the condenser.
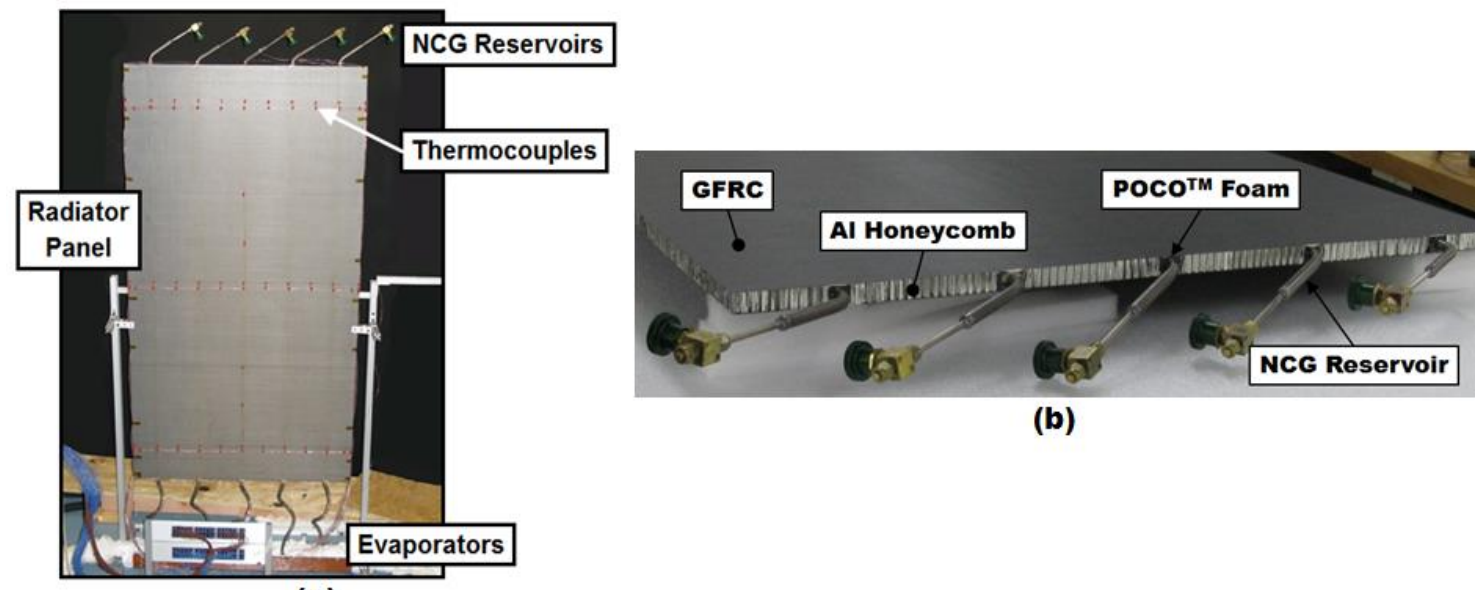

(b)

(a)

Figure 4. (a) VCHP radiator in testing configuration, (b) cross section of VCHP radiator. 


\section{Single Direct-Bond Facesheet Radiator Prototype}

\section{Fabrication}

A two-pipe VCHP assembly was used for fabrication of a small-scale demonstration panel with panel dimensions $30.5 \mathrm{~cm} \times 40.6 \mathrm{~cm} \times 0.036 \mathrm{~cm}$. The demonstration radiator was used for thermal cycling tests to determine if the bond adhesive could withstand stresses induced by the CTE mismatch between the titanium heat pipes and GFRC facesheet.

The CTE mismatch between a lightweight GFRC laminate and the titanium heat pipes posed a critical design risk for direct bond thermal cycle survival and thermal conduction/radiator function. The nominal CTE for Ti-6Al-4V is approximately $8.723 \mathrm{PPM} /{ }^{\circ} \mathrm{C}$ and the $\mathrm{CTE}$ for a standard GFRC composite laminate (K13D2U) is approximately 1.15 PPM $/{ }^{\circ} \mathrm{C}$ in the $\mathrm{x}$-direction (transverse direction) and $15.8 \mathrm{PPM} /{ }^{\circ} \mathrm{C}$ in the $\mathrm{y}$-direction (axial direction). Since the adiabatic section of the heat pipes incorporated a helical geometry to compensate for the CTE mismatch in the transverse direction, it was more critical for the GFRC laminate to match the CTE of titanium in the axial direction. After performing a Composites Analysis and Structural Materials (CASM) trade study, a CTE of $8.691 \mathrm{PPM} /{ }^{\circ} \mathrm{C}$ for the GFRC facesheet was achieved in the axial direction. Other facesheet properties resulting from this analysis included the following:

- $\quad 55 \%$ Fiber Volume

- $\quad 2.3$ mil Cured Ply thickness

- 6 Ply laminate $\left[0^{\circ},+30^{\circ},-30^{\circ} \mathrm{C}\right]_{\mathrm{s}}$

- Total laminate thickness: $0.036 \mathrm{~cm}$

- Thermal conductivity in the transverse direction: $367.4 \mathrm{~W} / \mathrm{m}-\mathrm{K}$

The two types of adhesive that were considered for the direct bonding application were a silver-filled epoxy (Eccobond 56C) and a film adhesive (Tencate RS-3). The film adhesive was selected because of its higher bond strength and ability to provide more intimate contact between the GFRC facesheet and the heat pipes. This film adhesive is a modified polycyanate resin, which possesses a maximum service temperature of $177^{\circ} \mathrm{C}$.

Figure 5 shows the completed direct-bond radiator assembly. Overall, the fabrication was considered a success. The panel appeared structurally sound with no visual imperfections or defects, and the heat pipes were well aligned in the vertical direction. However, due to the brittle nature of the composite facesheet, the engagement between the facesheet and the pipes was reduced rather significantly from the predicted value of $45-50 \%$ to approximately $25 \%$ of the pipe circumference, and the final ROC that was achieved was approximately $9.525 \mathrm{~mm}$.
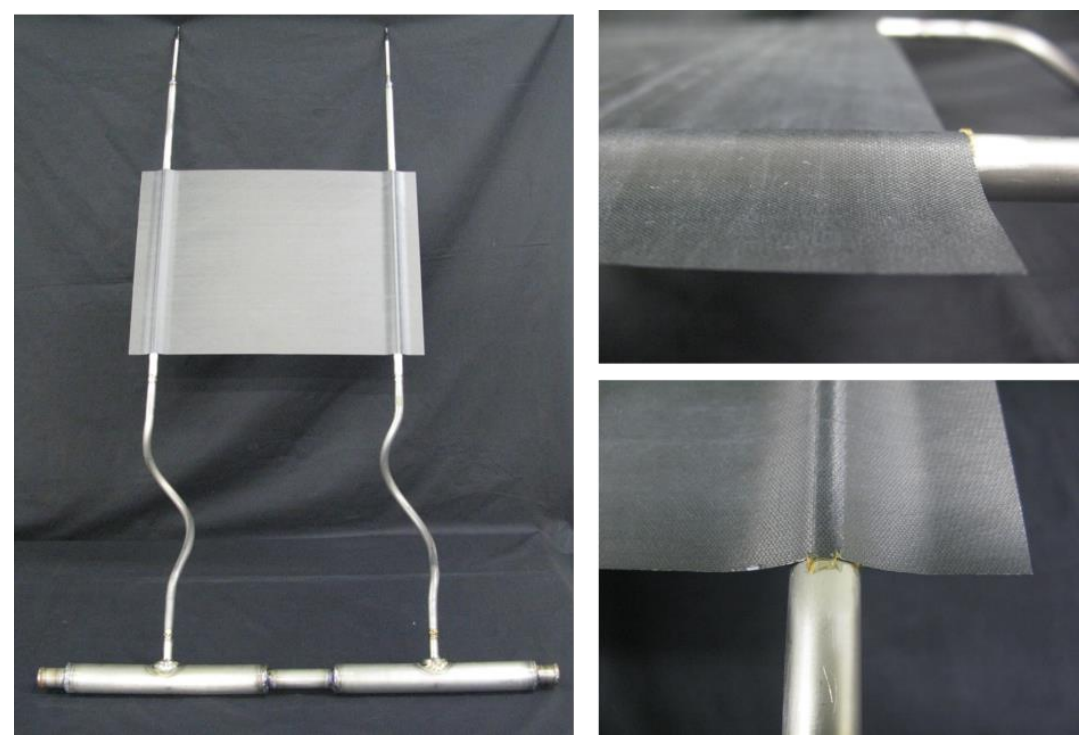

Figure 5. Completed small-scale direct-bond radiator assembly 


\section{Radiator Thermal Test Setup}

During thermal testing, the heat pipe radiator assembly must be maintained in the vertical direction to ensure that the heat pipes are gravity aided. The test stand shown in Figure 6 was fabricated from extruded aluminum and used to support the radiator for all tests conducted at ACT. The test stand also supports two pairs of aluminum/copper cold plates, which provide heat rejection for the radiator panel.

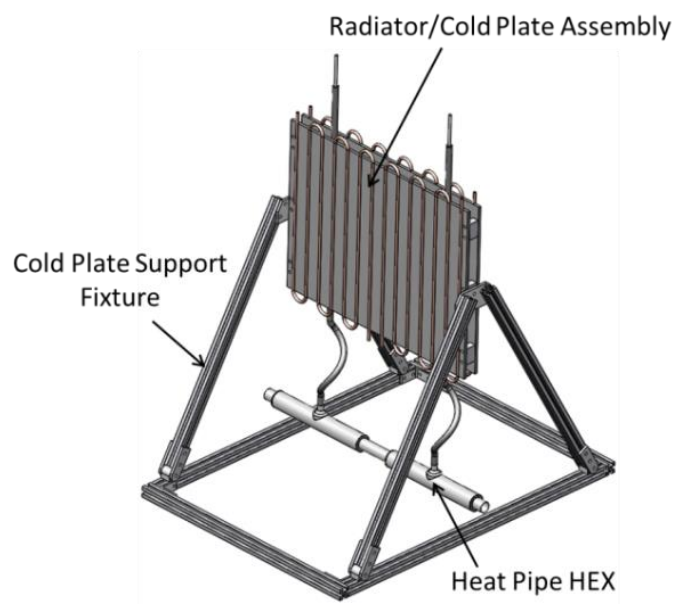

Figure 6. Radiator test stand and radiator/cold plate assembly

Figure 7 shows the locations of the thermocouples on the heat pipes and radiator panel. The thermocouples located along the surface of the heat pipes allowed the experimenter to verify proper heat pipe operation. At the panel level, each heat pipe thermocouple has a corresponding thermocouple on the facesheet side, directly opposite. The temperature difference between heat pipe surface and corresponding facesheet surface was used to quantify the bulk thermal resistance of the direct bond interface along each pipe.

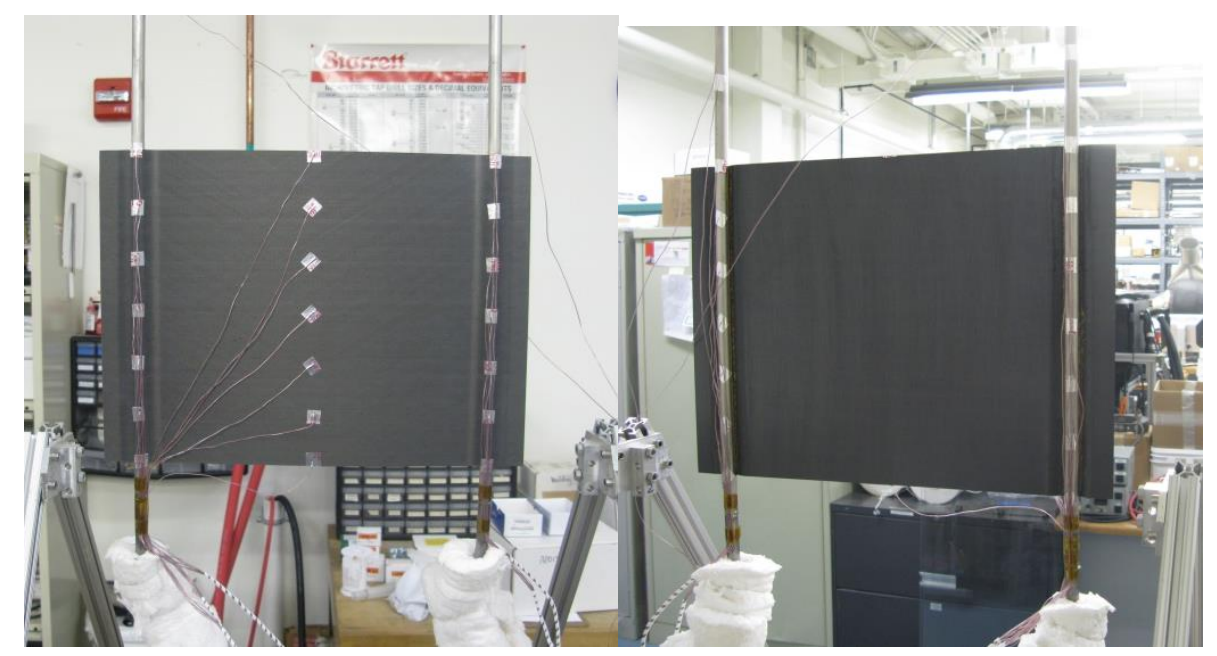

Figure 7. Thermocouple locations on heat pipes and radiator panel

Figure 8 shows the heat pipe radiator/cold plate assembly fully insulated and integrated with the thermal control system. The cold plates were supplied with liquid nitrogen $(\mathrm{LN})$ and the temperature was monitored at the center of the cold plate using tape-on thermocouples. The temperature of the cold plates was directly proportional to the flow of LN, which was regulated with an electronic proportional-integral-derivative (PID) controller. 


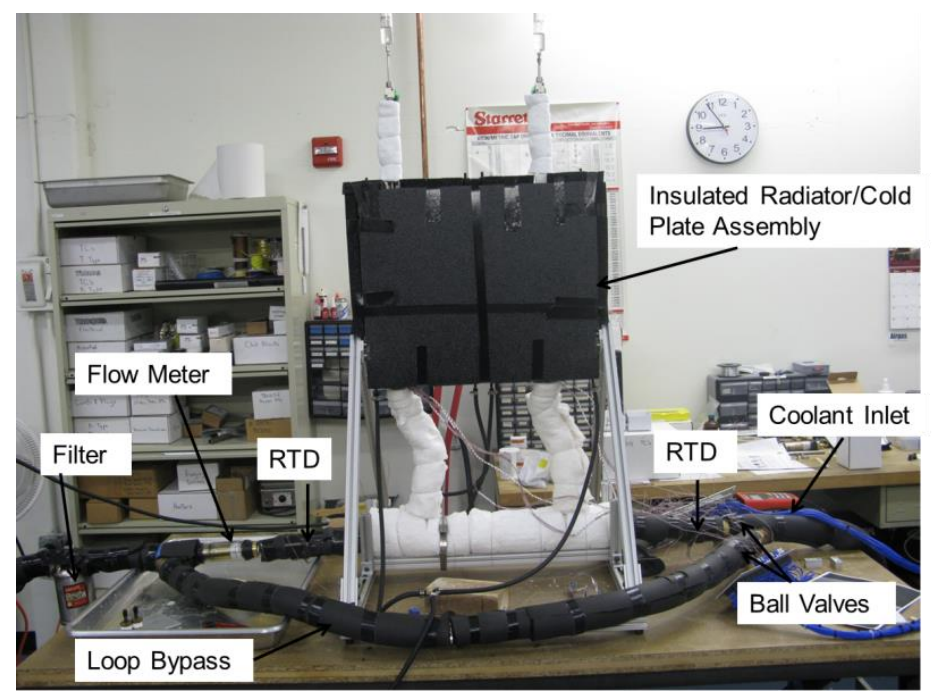

Figure 8. Radiator/cold plate assembly integrated with thermal control system

The simulated coolant flow (i.e. pressurized hot water), which was used to apply heat to the heat pipe evaporators, was pumped by a Sterling temperature control unit (TCU). A volumetric flow meter $(0-7.5 \mathrm{~L} / \mathrm{min}$ and filter that were mounted downstream of the heat exchanger outlet. During operation, the pump for the Sterling temperature control unit maintained a constant flow rate of $30 \mathrm{gal} / \mathrm{min}$. In order to regulate coolant flow through the evaporator heat exchanger, a by-pass line and two ball valves were installed into the system. Intrusive resistance temperature detectors (RTDs) were used to monitor the coolant temperature at the inlet and outlet of the evaporator manifold. By knowing the coolant inlet and outlet temperatures and the volumetric flow rate, the power being dissipated by the heat pipe radiator can be determined from calorimetry calculations. Readings from the TC probes and RTDs were directly inputted into a Keithley data-acquisition (DAQ) system for real-time monitoring and data-keeping. In all, the DAQ monitored and recorded 50 TC channels and 2 RTD channels.

\section{Radiator Test Methodology and Procedure}

Two different types of thermal tests were conducted to determine the durability of the bond between the GFRC facesheet and the titanium/water heat pipes over a range of operating conditions. The first test was the thermal performance test that was used to determine baseline values for the thermal resistance of the direct-bond at various operating temperatures. The second test was the thermal cycling test that involved thermal cycling as a means of inducing CTE stresses at the bond interface. Another purpose for the thermal cycling test was to expose the direct bond joint at extreme temperatures in an alternate fashion. After thermal cycling, the thermal performance test was repeated to see if the thermal resistance of the bond changed as a result of CTE induced stresses. An increase in thermal resistance would indicate that the bond integrity has degraded.

For the thermal performance test, ACT charged the heat pipes as CCHPs (for simplicity) and attempted to vary the bond operating temperature by decreasing the cold plate temperature (i.e. sink temperature), while the inlet coolant temperature was held constant. It was expected that as the sink temperature dropped, the heat pipe condenser temperature would also decrease to accommodate the increase in power carried by each heat pipe.

For the thermal cycling test, non-condensable gas (argon) was added to the heat pipes to allow the condenser temperature to closely follow the sink temperature. The system was thermally cycled by simultaneously adjusting the sink and coolant temperature between hot and cold conditions. During hot conditions, the non-condensable gas is pushed into the reservoir and the condenser/radiator area is completely available for heat rejection. At the cold temperature conditions, the coolant temperature is kept high enough to avoid freezing, but the sink temperature is sufficiently cold to freeze the heat pipe working fluid throughout the condenser/radiator section. Two sets of thermal cycling tests were performed to simulate moderate thermal cycling and more rigorous thermal cycling. The difference between the two tests is the cold sink temperature that was $-70^{\circ} \mathrm{C}$ for the first test and $-100^{\circ} \mathrm{C}$ for the second test. 


\section{Test Results}

Baseline Thermal Performance Test Results

Figure 9 shows temperature versus time for the baseline thermal performance test. This plot shows how various temperatures and temperature differences were influenced by the reduction in cold plate temperature. Note that heat pipes 1 and 2 represent the heat pipe closest to the coolant inlet and outlet, respectively; and the vapor temperatures were taken as the surface temperature at the adiabatic section of each heat pipe.

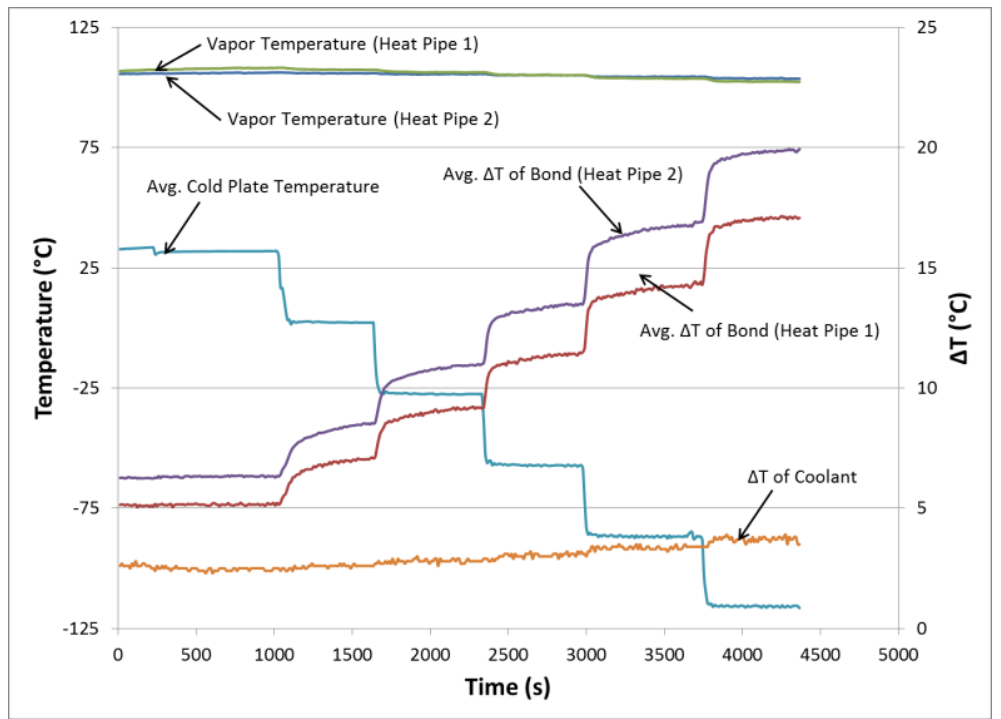

Figure 9. Temperature versus time plot for the baseline thermal performance test (before thermal cycling)

From the plot above, it can be seen that as the cold plate temperature was reduced, the heat pipe vapor temperatures decreased slightly $\left(\sim 3.5^{\circ} \mathrm{C}\right)$. This result was considered unsatisfactory, since the original objective the experiment was to quantify thermal resistances of the bond over a wide range of operating temperatures. The cause of this minimal delta temperature was attributed to a large free convection coefficient generated by inadequate insulation and vertical orientation of the radiator. This was confirmed by observing the change in power output as a function of cold plate temperature (seen in Figure 10).

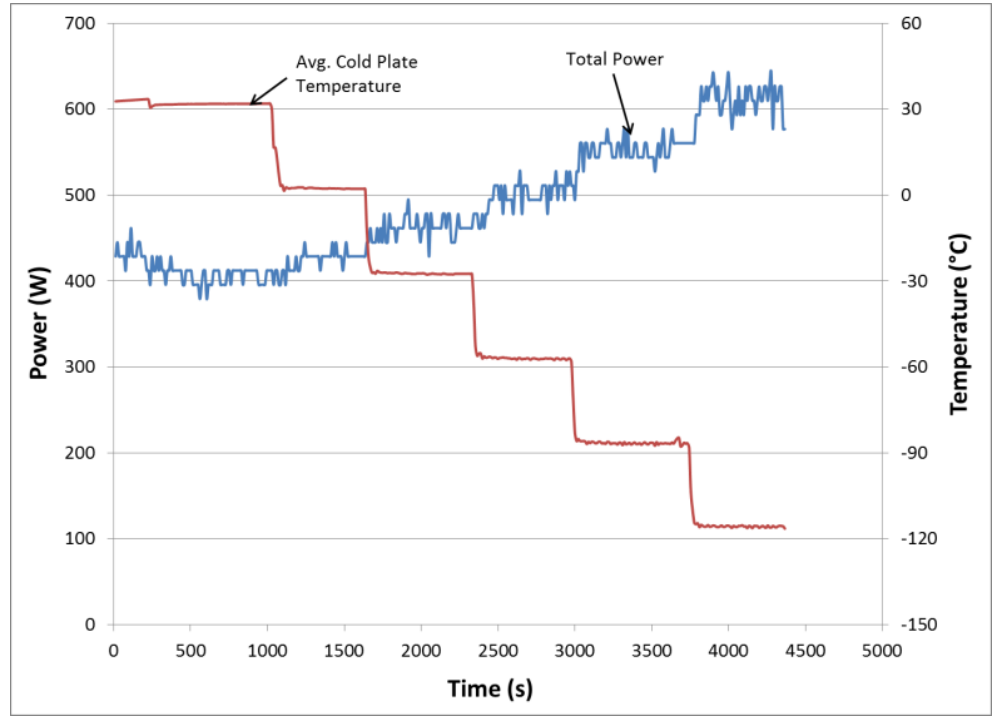

Figure 10. Power versus time for the baseline thermal performance test (before thermal cycling) 
The plot in Figure 10 shows that the radiator power output (measured by calorimetry of the coolant) increased from approximately 400 to $600 \mathrm{~W}$ as the sink temperature was reduced from $30^{\circ} \mathrm{C}$ to $-120^{\circ} \mathrm{C}$. If the dominant mode of heat transfer was radiation, as intended, the theoretical reduction in vapor temperature should be roughly $100^{\circ} \mathrm{C}$. In addition, the experiment presented here represents a second test attempt that was performed after additional insulation was applied. The vapor temperature reduction from the first trial non-existant prior to adding insulation, which gave further confirmation that free convection was dominant over the component of radiation.

Figure 11 and Figure 12 show the results for the thermal performance test conducted after thermal cycling. Once again, the vapor temperature did not decrease as much as expected with reduction in sink temperature. However, for this case, the radiator was clearly more sensitive to changes in sink temperature than the first test, as indicated by the larger range of power output $(\sim 400-1000 \mathrm{~W})$ and the overall decrease in vapor temperature $\left(\sim 6^{\circ} \mathrm{C}\right)$. The reason for this outcome was undetermined, but was likely due to an unintentional variation between the test conditions used in each experiment. Regardless of the reason for the larger power output, the outcome was of no consequence since the original plan to evaluate the bond heat flux over a wide range of operating temperatures was already abandoned. Nevertheless, by comparing the temperature difference profile through the bond along each heat pipe (i.e. temperature difference between condenser pipe surface and corresponding GFRC root) before and after thermal cycling should still provide an indication of the bond's ability to withstand any stresses caused by CTE mismatch.

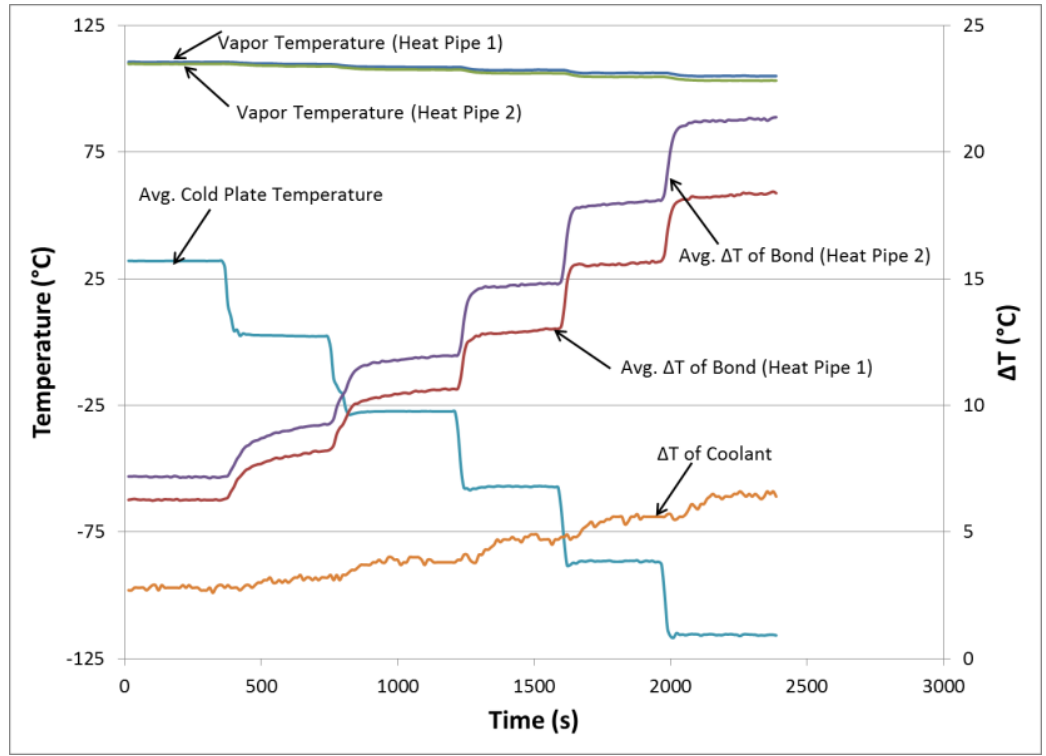

Figure 11. Temperature versus time for the thermal performance (post thermal cycling) 


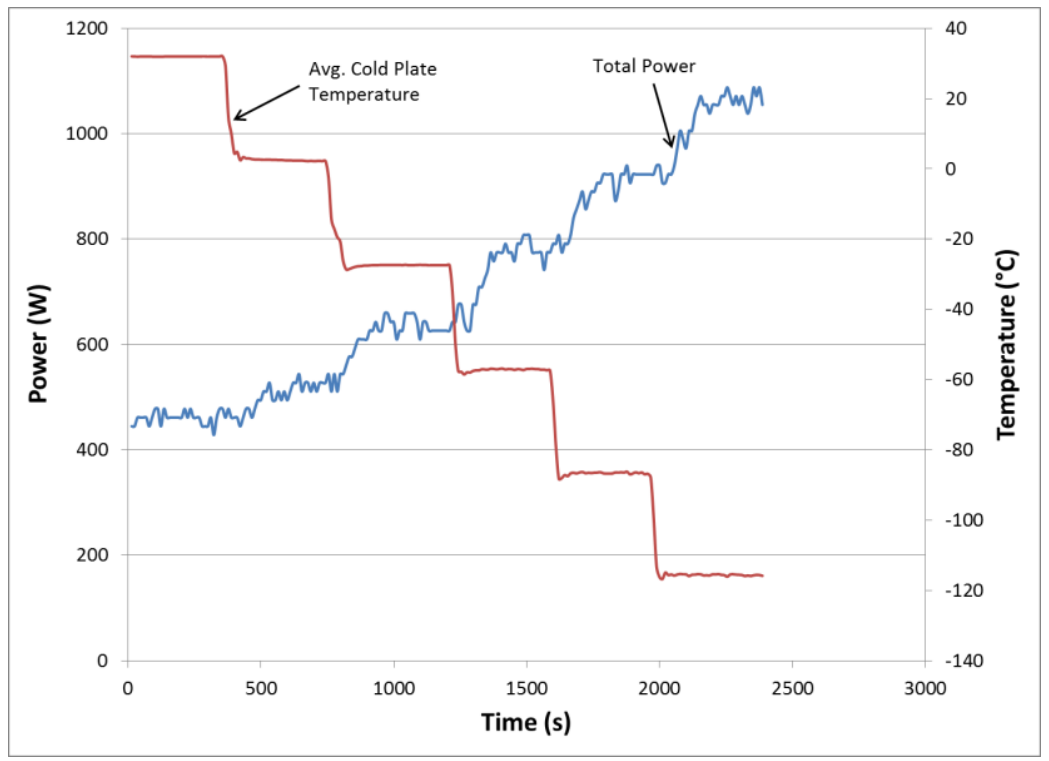

Figure 12. Total power output versus time for thermal performance test (post thermal cycling)

Figure 13 shows the effective delta temperature of the bond as a function of the location along the condenser of heat pipe 1 (i.e. heat pipe closest to the coolant inlet) for the cases before and after thermal cycling was performed. For both cases, the local bond temperature differences are shown for the two sink temperature extremes used during the thermal performance tests $\left(30^{\circ} \mathrm{C}\right.$ and $\left.-120^{\circ} \mathrm{C}\right)$. The reason for the discrepancy between the temperature difference profile before and after thermal cycling was due to the higher heat flux present in the second thermal performance test, as mentioned previously. By examining one sink temperature condition at a time, and ignoring the discrepancy of the delta bond temperatures at a given condenser location, it can be seen that the delta temperature profile along the condenser is nearly identical for the tests before and after thermal cycling. This result was seen as a clear indication that the adhesive bond was not deteriorating as a result of CTE induced stresses. However, the plots do indicate that there may be some non-uniformities in the adhesive bond layer. This apparent non-uniformity appeared to be particularly true for heat pipe 2 (i.e. heat pipe closest to the coolant exit), as seen in Figure 14.

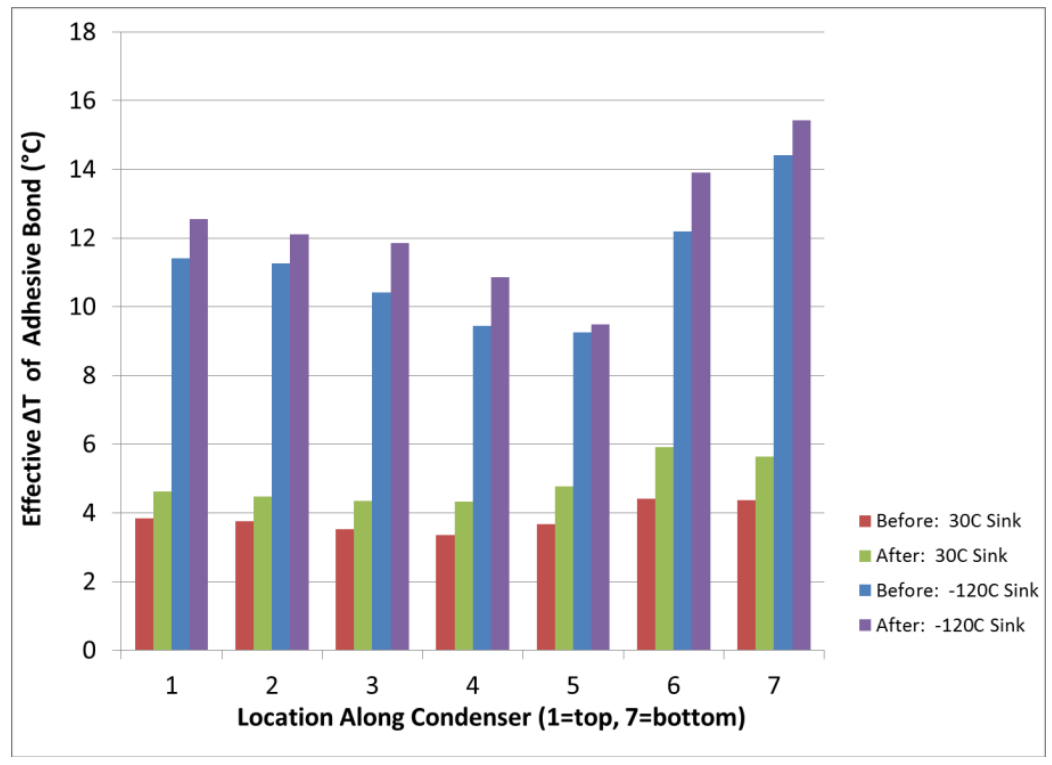

Figure 13. Comparison of effective bond delta temperatures along heat pipe 1 before and after thermal cycling for $30^{\circ} \mathrm{C}$ and $-120^{\circ} \mathrm{C}$ sink temperature conditions 


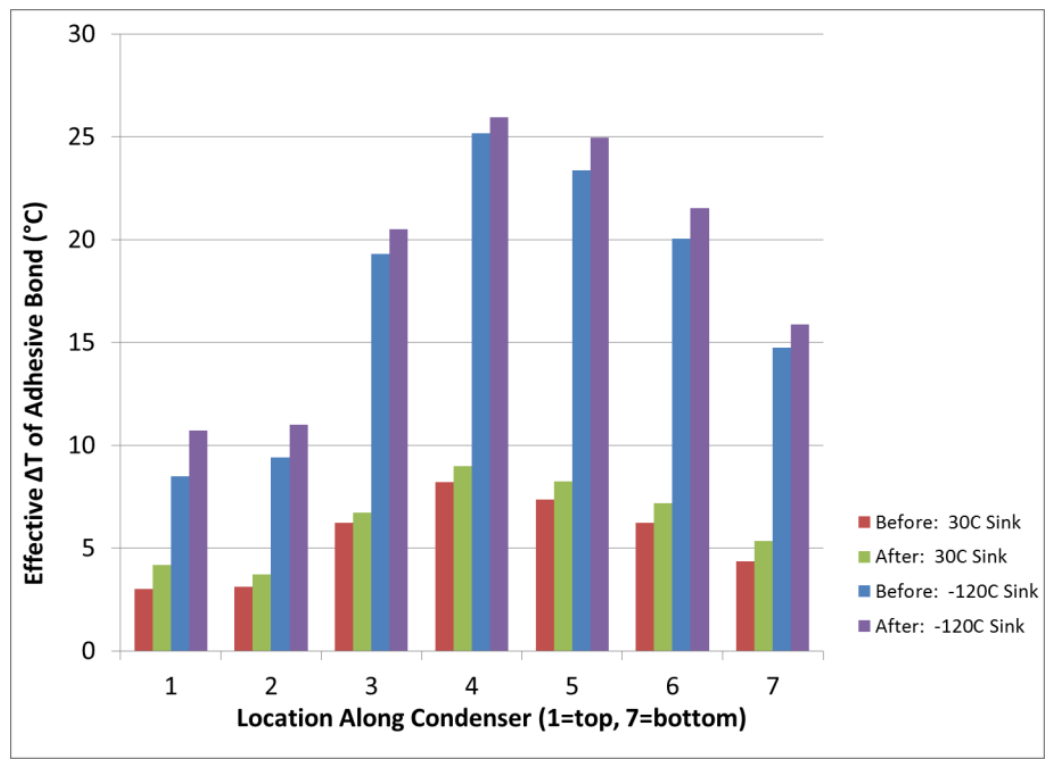

Figure 14. Comparison of effective bond delta temperatures along heat pipe 2 before and after thermal cycling for $30^{\circ} \mathrm{C}$ and $-120^{\circ} \mathrm{C}$ sink temperature conditions

From Figure 14, it was clear that, like heat pipe 1, there was no sign of bond adhesive degradation as indicated by the consistency of the delta temperature profile before and after thermal. However, for a given sink temperature, the deviation of delta bond temperatures along heat pipe 2 was much more significant than seen in heat pipe 1 . This indicated that the bond uniformity was relatively poor compared to heat pipe 1 . This presumption was verified by using an FLIR infrared (IR) camera to capture images of the thermal gradients along each heat pipe while operating in ambient conditions (seen in Figure 15). From the IR image, it was evident that heat pipe 2 had a relatively larger thermal gradient (indicated by the circled region) in the same general location indicated by the large delta temperatures seen in Figure 14.

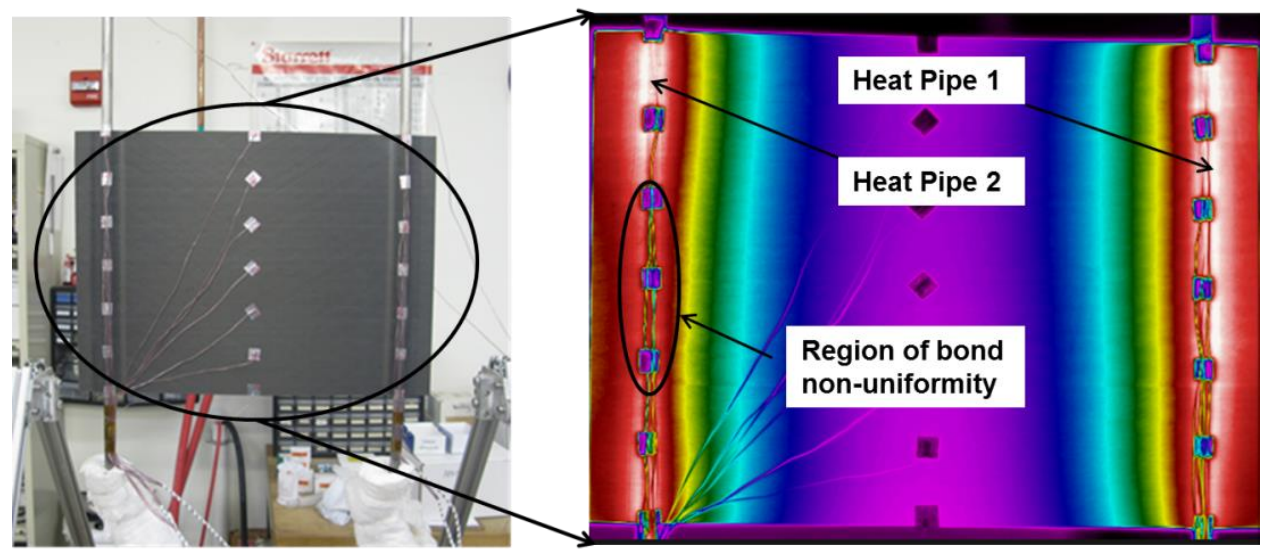

Figure 15. Infrared image of single facesheet radiator prototype at ambient $\left(21^{\circ} \mathrm{C}\right)$ conditions

Based on the results presented in this section, it was deduced that the combination of laminate layup and strength of the adhesive bond were sufficient to prevent degradation of the bond while the radiator underwent thermal cycling. On the other hand, the non-uniform nature of the adhesive bond poses a serious threat to the success of extended operation. If awarded the Phase II program, ACT and VST will make bond uniformity and overall bond strength a high priority for development. 


\section{Thermally Cycling Test Results}

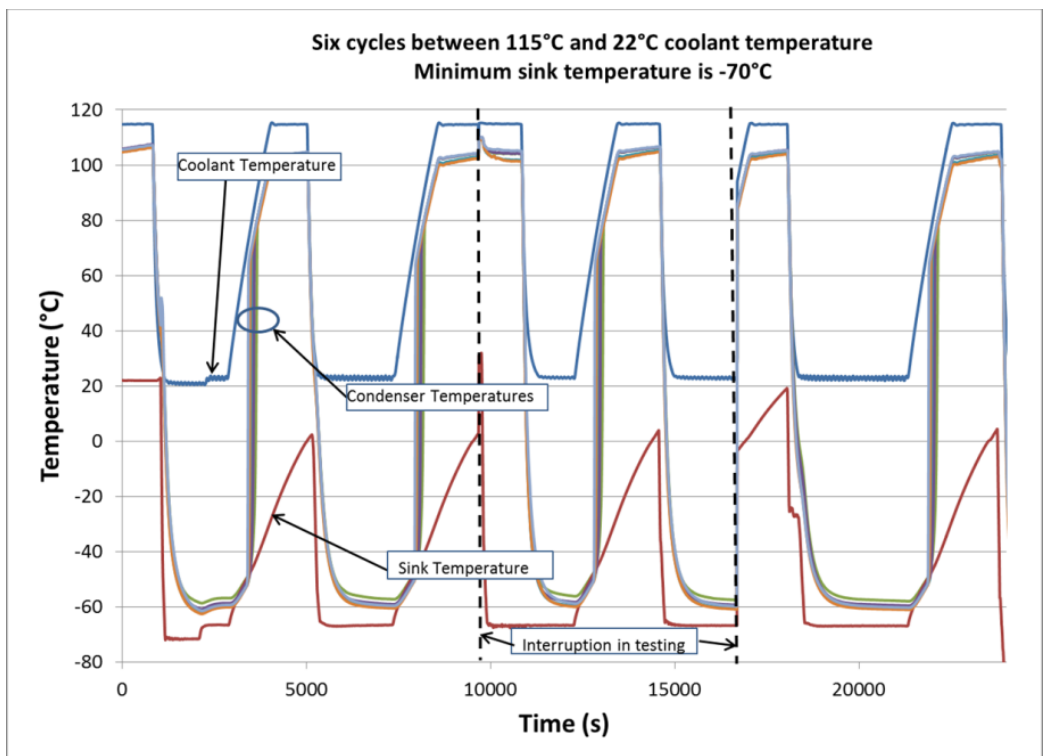

Figure 16. First set of thermal cycling: six cycles for the cold heat sink temperature of $-\mathbf{7 0}^{\circ} \mathrm{C}$

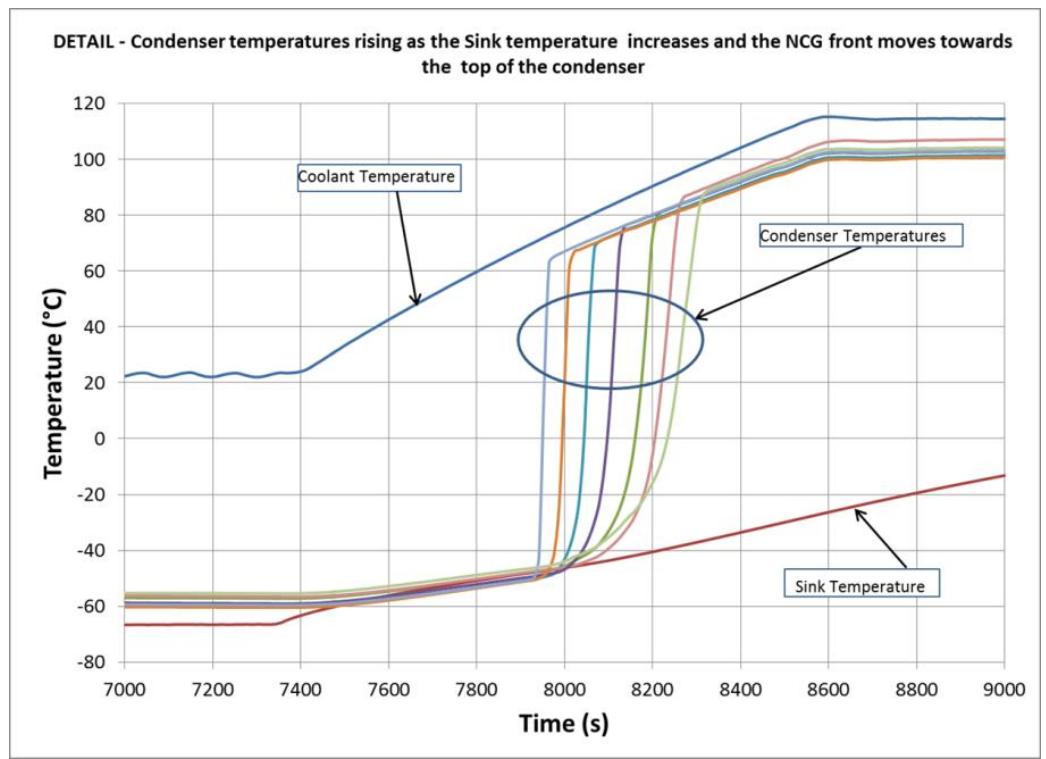

Figure 17. Detail during the temperature ramp up for the $-\mathbf{7 0}^{\circ} \mathrm{C}$ cold heat sink temperature case: behavior of the variable conductance condenser 


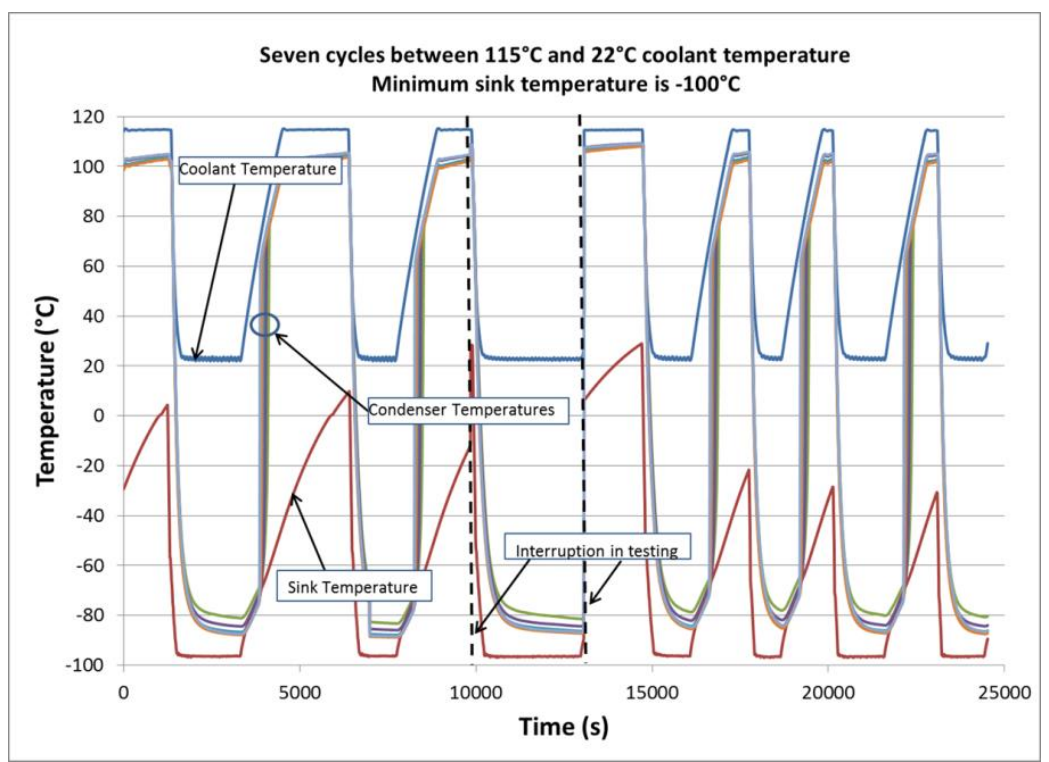

Figure 18. Second set of thermal cycling: seven cycles for the cold heat sink temperature of $-100^{\circ} \mathrm{C}$

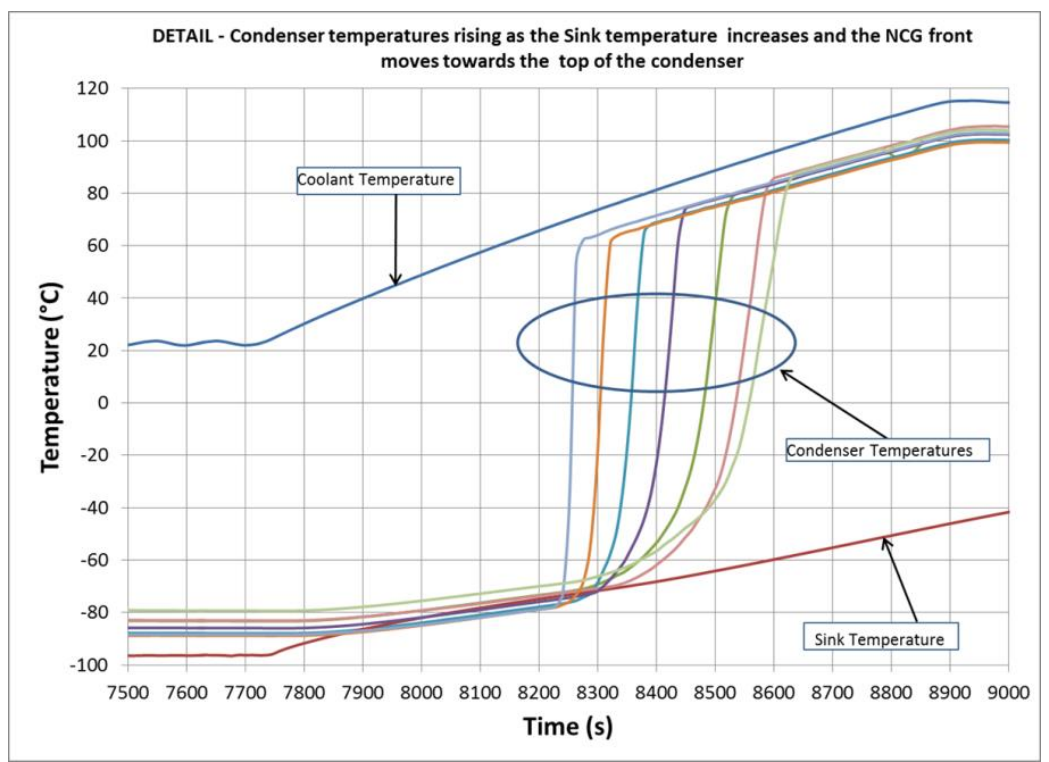

Figure 19. Detail during the temperature ramp up for the $-100^{\circ} \mathrm{C}$ cold heat sink temperature case: behavior of the variable conductance condenser

As mentioned above, the thermal cycling was entirely carried in between (chronologically) the two identical thermal performance tests. The main reason was that through thermal cycling, the direct bond joint was cyclically exposed to extreme temperatures, hot and cold, with potential risk of damaging the joint quality. The second thermal performance results (after thermal cycling) were compared to the initial ones to observe changes in thermal resistance. While the comparison was presented above, in this section the actual results from thermal cycling testing are presented.

Figure 16 shows the first set of thermal cycling results where the cold sink temperature set point was $-70^{\circ} \mathrm{C}$. Only the coolant, heat sink (cold plates) and condenser (of one pipe only) temperatures are represented. The seven condenser temperatures that are represented are the average between the vapor and root temperatures at certain locations along the condenser. Six cycles can be observed where the coolant and sink temperatures swing together 
between $115^{\circ} \mathrm{C}$ and $20^{\circ} \mathrm{C}$ for the coolant and 21 and $-70^{\circ} \mathrm{C}$ for the sink. It can be observed that the high end for the sink was not always $21^{\circ} \mathrm{C}$ but lower. This is because reaching that high temperature for the sink was not relevant since the condenser (with the bonds were already at their temperature peaks. The most relevant temperature during these cycles are the seven condenser temperatures that ion fact represent the joint temperatures. It can be observed that the direct bond joint temperature varied between 109 and $-68^{\circ} \mathrm{C}$ during each cycle. In Figure 17, a detail is shown to observe the VCHP behavior during one of the temperature ramp ups.

Figure 18 and Figure 19 show the results from the second thermal cycling experiment were the cold sink temperature was lowered to $-100^{\circ} \mathrm{C}$. As observed in Figure 18 the temperature of the direct bond joint varied between 109 and $-90^{\circ} \mathrm{C}$ during each cycle. Again, in Figure 19, a detail is shown to observe the VCHP behavior during one of the temperature ramp ups. In summary, the direct bond joints were exposed to a total of 13 cycles where the temperatures were considered extreme. However, these extremes were not as severe as would be experienced a in a real lunar application.

\section{Conclusions}

A composite laminate facesheet was successfully bonded to the titanium/water heat pipes of a prototype assembly. The prototype was tested to evaluate thermal performance, as well as the ability of the direct bonds to withstand thermally induced stresses during thermal cycling tests. The integrity of the direct bond joints was compared before and after thermal cycling, and no signs of bond degradation were observed. However, the bond adhesive proved to be less uniform for one of the heat pipe bonds. Several methods to alleviate are currently being addressed and include using more sophisticated tooling techniques, increasing the diameter of the heat pipe condenser section, and co-curing the GFRC facesheet by using the inherent resin within the laminate as an adhesive.

\section{Acronyms}

$\begin{array}{ll}\text { CCHP } & \text { Constant Conductance Heat Pipe } \\ \text { CTE } & \text { Coefficient of thermal expansion } \\ \text { GFRC } & \text { Graphite Fiber Reinforced Composite } \\ \text { VCHP } & \text { Variable Conductance Heat Pipe }\end{array}$

\section{Acknowledgments}

This research was sponsored by NASA Glenn Research Center under contract NNX13CC45P. Any opinions, findings, and conclusions or recommendations expressed in this article are those of the authors and do not necessarily reflect the views of the National Aeronautics and Space Administration. We would like to thank Maxwell Briggs who was the contract technical monitor; and Theodore Stern and Nick Walmsley of Vanguard Space Technologies, Inc. who were responsible fabricating prototype GFRC facesheet and directly bonding it to the heat pipe assembly.

\section{References}

${ }^{1}$ L. Mason, D. Poston, and L. Qualls, "System Concepts for Affordable Fission Surface Power", NASA Technical Memorandum 215166 (2008).

${ }^{2}$ Mason, L. S., Oleson, S. R., Mercer, C. R., and Palac, D. T., "Nuclear Power System Concepts for Electric Propulsion Missions to Near Earth Objects and Mars," Nuclear and Emerging Technologies for Space (NETS-2012), The Woodlands, TX, March 21-23, 2012.

${ }^{3}$ Anderson, W. G., Peters, C. J., Muzyka, B. J., Hartenstine, J. R., and Williams, G., "VCHP Radiators for Lunar and Martian Environments," Final Report to NASA GRC, Contract No. NNX09CA43C, June 22, 2011. 